\title{
Elaboração de salsichas de frango com redução de gordura e adição de inulina
}

\section{Elaboration of chicken sausages with fat reduction and inulin addition}

\author{
Chimenes Darlan Leal de Araujo1, Gilmar Freire da Costa2* (1), \\ Fernando Luiz Nunes de Oliveira ${ }^{3}$, Geíza Alves Azerêdo ${ }^{1}$
}

${ }^{1}$ Universidade Federal da Paraíba (UFPB), Departamento de Gestão e Tecnologia Agroindustrial, Bananeiras/PB Brasil

${ }^{2}$ Universidade Estadual de Campinas (UNICAMP), Faculdade de Engenharia de Alimentos, Departamento de

Tecnologia de Alimentos, Campinas/SP - Brasil

${ }^{3}$ Universidade Federal da Paraíba (UFPB), Departamento de Agricultura, Bananeiras/PB - Brasil

*Corresponding Author: Gilmar Freire da Costa, Universidade Estadual de Campinas (UNICAMP), Faculdade de Engenharia de Alimentos, Departamento de Tecnologia de Alimentos, Rua José Duarte, 175, Campinas/SP - Brasil, e-mail: gilmarfreiredacosta@gmail.com

Cite as: Araujo, C. D. L., Costa, G. F., Oliveira, F. L. N., \& Azerêdo, G. A. (2021). Elaboration of chicken sausages with fat reduction and inulin addition. Brazilian Journal of Food Technology, 24, e2019334. https://doi.org/10.1590/1981-6723.33419

\begin{abstract}
Resumo
Objetivou-se com este trabalho determinar os efeitos da substituição parcial e total da gordura por inulina nos parâmetros de qualidade de salsichas de frango. Três formulações foram desenvolvidas: Controle (F1) e dois níveis de inclusão de inulina: 2,5\% (F2) e 5\% (F3). Parâmetros de umidade, cinzas, proteínas, lipídeos, carboidratos, pH, atividade de água e cor $\left(L^{*}, a^{*}\right.$ e $\left.b^{*}\right)$ foram analisados. O perfil tecnológico também foi analisado por meio da estabilidade da emulsão, perda de peso por cozimento, perda de peso por exsudação e força de cisalhamento. Os atributos sensoriais pesquisados foram cor, aparência, textura, sabor, aceitação geral, bem como teste de intenção de compra. A adição de $2,5 \%$ de inulina na formulação $\mathrm{F} 2$ verificou-se uma redução na perda de água durante o cozimento, perda de peso por exsudação, bem como aumento da estabilidade da emulsão comparada às demais formulações. A formulação com $5 \%$ de inulina apresentou baixo teor de gordura, baixa força de cisalhamento e elevados teores de cinzas e carboidratos comparativamente à formulação controle. Não houve alterações no pH e na atividade de água. Em relação à cor, a inclusão de inulina teve efeito significativo $(p<0,05)$ para a luminosidade $\left(L^{\star}\right)$ na superfície interna das salsichas. $O$ valor de $b^{*}$ também foi significativo $(p<0,05)$ na formulação $(F 3)$ para a superfície interna e na formulação F1 na superfície externa. A adição de inulina, em especial na formulação (F3), resultou em valores mais altos nas avaliações de aparência, textura e sabor em relação às demais formulações, o que refletiu na maior intenção de compra. Sendo assim, pode-se afirmar que foi possível a redução de $50 \%$ e $100 \%$ de gordura com a adição de $2,5 \%$ e $5 \%$ de inulina, sem redução na qualidade das salsichas.
\end{abstract}

Palavras-chave: Alimentos funcionais; Consumidor; Produtos cárneos; Parâmetros qualitativos; Processamento; Saúde pública. 


\begin{abstract}
This work aimed to determine the effects of partial and total fat substitution by inulin on the quality parameters of chicken sausages. We developed three formulations, control (F1) and two levels of inclusion of inulin, 2.5\% (F2) and $5 \%$ (F3). Parameters of moisture, ash, protein, lipids, carbohydrates, $\mathrm{pH}$, water activity and color ( $\mathrm{L} * \mathrm{a}$ * and $\mathrm{b} *)$ were analyzed. The technological profile was also analyzed through the stability of the emulsion, weight loss by cooking, weight loss by exudation and shear force. The sensory attributes surveyed were color, appearance, texture, flavor, general acceptance as well as a purchase intention test. The addition of 2,5\% of inulin to formulation F2 led to a reduction in water loss during cooking, weight loss by exudation as well as an increase in emulsion stability compared to other formulations. While the $\mathrm{F} 3$ formulation with $5 \%$ of inulin presented low-fat content, low shear strength and high levels of ash and carbohydrate compared to the control formulation. There were no changes in $\mathrm{pH}$ and water activity. Regarding color, the inclusion of inulin had a significant effect $(p<0.05)$ for the luminosity $(L *)$ on the inner surface of the sausages. The $b$ * value was also significant $(p<0.05)$ in the formulation $(F 3)$ for the inner surface and in the formulation F1 on the outer surface. The addition of inulin, especially in the formulation (F3), resulted in higher values of appearance, texture, and flavor compared to the other formulations, which reflected in the higher purchase intention. Thus, it was observed a reduction of $50 \%$ and $100 \%$ of fat with $2,5 \%$ and $5 \%$ of inulin addition without reduction of the sausages quality.
\end{abstract}

Keywords: Functional foods; Consumer; Meat products; Qualitative parameters; Processing; Public health.

\title{
1 Introdução
}

Segundo Hue (2011), as categorias que representam os produtos cárneos são salsicha, salsichão, linguiça, presunto, apresuntado, salame, mortadela, copa, lombo, presunto parma e bacon. Dentre estes, a salsicha, salsichão e a mortadela representam cerca de $82 \%$ do volume de embutidos comercializados.

A salsicha, por sua vez, vem se tornando mais popular devido às suas características sensoriais, bem como facilidade e rapidez no preparo e com boa aceitação pelo consumidor. Ao mesmo tempo, o seu consumo tem sido criticado, devido à elevada quantidade de sal e gordura adicionados em sua formulação, uma vez que são considerados fatores de risco no desenvolvimento de doenças crônicas, como as doenças cardiovasculares, a obesidade, hipertensão e câncer (Almeida, 2015; Hygreeva et al., 2014; Horita et al., 2011; Park et al., 2012).

Neste sentido, o Departamento de Agricultura dos EUA (United States Department of Agriculture, 2002) recomenda a redução no consumo de gordura saturada e, ao mesmo tempo, cria programas para obter produtos processados com baixo teor de gordura, mesmo sabendo de sua contribuição na aparência e sabor dos embutidos (Brewer, 2012). Desse modo, a adição de ingredientes funcionais, como a inulina, na substituição parcial e/ou total de gordura em salsichas, vem se tornando uma alternativa promissora (Bolumar et al., 2015; Henning et al., 2016; Marchetti et al., 2017; Slima et al., 2018).

A inulina é um dos ingredientes mais utilizados em produtos cárneos, sendo destacada como potencial fonte de fibra dietética solúvel, com baixo valor calórico, extraída comercialmente da raiz da chicória. É considerado um ingrediente prebiótico, uma vez que não é digerível e estimula seletivamente a multiplicação e a atividade de bactérias intestinais consideradas benéficas (Saad et al., 2011). Graças a seus efeitos benéficos e de grande importância para a indústria alimentícia, fibras dietéticas têm sido largamente empregadas em vários alimentos, como leite, iogurte, queijo, chocolate e produtos cárneos, com o intuito de substituir a gordura e proporcionar efeitos benéficos à saúde dos consumidores (Sah et al., 2016).

Neste contexto, a utilização da inulina em produtos cárneos como substituto da gordura ou como um incremento de fibras benéficas ao organismo humano vem mostrando bons resultados sensoriais, físicoquímico e tecnológico. Neste âmbito de pesquisa, Mendoza et al. (2001) obtiveram resultados satisfatórios utilizando a inulina como substituto da gordura saturada em salsichas fermentadas, em que observaram que a adição da inulina proporcionou elasticidade e textura macia tendo boa aceitabilidade global, além de que obtiveram uma salsicha com teor reduzido de gordura, alto teor de proteína, minerais e carboidratos, enriquecendo a qualidade nutricional deste produto cárneo. 
Por conseguinte, Bernadino Filho et al. (2013) utilizaram a inulina como ingrediente funcional prebiótico em hambúrguer bovino com teor reduzido de gordura, e o estudo mostrou que a inulina foi eficaz, sendo uma alternativa para a redução de gordura em hambúrguer bovino, sem prejudicar suas características físicoquímica e tecnológica, além disso, produziu um produto com propriedades funcionais que proporciona benefícios à saúde do consumidor.

Sendo assim, considerando a importância econômica do setor de produtos cárneos e a exigência do mercado consumidor por produtos mais saudáveis, objetivou-se com este trabalho o desenvolvimento de salsichas com a adição de inulina como um substituto parcial e total da gordura e avaliar os impactos sobre as características físico-químicas, perfil microbiológico, tecnológico e atributos sensoriais.

\section{Material e métodos}

\subsection{Obtenção das matérias-primas e ingredientes}

As carnes de aves (tipo peito de frango), bem como a pele de aves, foram adquiridas em estabelecimento comercial da cidade de Bananeiras - PB. O amido de mandioca e o nitrito foram provenientes do laboratório de desenvolvimento de produtos cárneos da Universidade Federal da Paraíba, Campus III, Bananeiras - PB (UFPB). A proteína isolada de soja e o mix salsicha (sal de cura, salsa desidratada, eritorbato de sódio, emulsificante e tripolifosfato de sódio) foram adquiridos da empresa Bremil - Indústria de Produtos Alimentícios LTDA - RS, a fumaça líquida da empresa Citromax essências LTDA e a inulina foi obtida da empresa Sweetmix Ind. Com. Imp. Exp. Ltda.

\subsection{Processamento da salsicha de frango}

O processo de fabricação das salsichas foi realizado no laboratório de desenvolvimento de produtos cárneos da Universidade Federal da Paraíba, Campus III, Bananeiras - PB. O processamento das salsichas foi feito, conforme expresso na Tabela 1; sendo que a formulação (F1) tratou-se da formulação controle, a (F2) foi aquela em que houve redução parcial da gordura por inulina e (F3) aquela em que houve redução total da gordura por inulina.

Tabela 1. Formulação de salsichas com redução parcial e total da gordura por inulina.

\begin{tabular}{|c|c|c|c|}
\hline \multirow{2}{*}{ Composição das salsichas } & \multicolumn{3}{|c|}{ Formulações (\%) } \\
\hline & F1 & F2 & F3 \\
\hline CMS de frango & 60 & 60 & 60 \\
\hline Água & 13,21 & 13,21 & 13,21 \\
\hline Sal & 1,9 & 1,9 & 1,9 \\
\hline Mix Salsicha & 1 & 1 & 1 \\
\hline${ }^{*}$ Pele de aves & 5 & 2,5 & 0 \\
\hline Inulina & 0 & 2,5 & 5 \\
\hline Fécula de mandioca & 2 & 2 & 2 \\
\hline PIS & 4 & 4 & 4 \\
\hline Nitrito & 0,3 & 0,3 & 0,3 \\
\hline Pasta de alho & 0,3 & 0,3 & 0,3 \\
\hline Carne de aves & 7 & 7 & 7 \\
\hline Miúdo (fígado) & 5 & 5 & 5 \\
\hline Aroma de fumaça & 0,24 & 0,24 & 0,24 \\
\hline Máster coral & 0,05 & 0,05 & 0,05 \\
\hline
\end{tabular}

CMS: Carne mecanicamente separada de frango; PIS: Proteína isolada de soja. *Pele de aves: Utilizada como gordura. 
Inicialmente, as matérias-primas cárneas que estavam refrigeradas a $5^{\circ} \mathrm{C}$ foram cortadas em pequenos pedaços e moídas em moedor de carne CAF, aço inox, Bivolt -CAF08 com diâmetro de saída da carne de $5,4 \mathrm{~cm}$. Após esta etapa, a carne moída passou pela etapa de emulsificação em cutter de aço inox para completa mistura dos ingredientes. Ao fim do processo de emulsificação, a massa foi embutida em tripas celulósicas artificiais calibre $22 \mathrm{~mm}$ de marca Nipp casing e cozidas a uma temperatura de $75{ }^{\circ} \mathrm{C} \pm 2{ }^{\circ} \mathrm{C}$ por três horas. Após o cozimento, as salsichas foram resfriadas durante 5 minutos em água gelada em temperatura ambiente, posteriormente as salsichas tiveram seus envoltórios retirados manualmente, com o auxílio de facas de aço inox. Em seguida, as salsichas foram embaladas a vácuo e armazenadas em câmara de congelamento em temperatura a $-18^{\circ} \mathrm{C}$.

\subsection{Análises físico-químicas}

As avaliações físico-químicas foram realizadas no laboratório de análise físico-química de alimentos da Universidade Federal da Paraíba, Campus III, Bananeiras - PB. As determinações de umidade, cinzas, pH, lipídeos, proteínas, atividade de água e carboidratos foram realizadas em triplicata seguindo os procedimentos metodológicos descritos pela AOAC (Association of Official Analytical Chemists, 2005). As três formulações de salsichas também foram submetidas à avaliação colorimétrica utilizando um colorímetro Colorquest XE HunterLab, com o iluminante padrão D65 e observador a $10^{\circ}$ (sistema CIE-LAB). Foi feito o mensuramento da luminosidade $\left(\mathrm{L}^{*}\right)$, índice de verde-vermelho $\left(\mathrm{a}^{*}\right)$ e índice de azul-amarelo $\left(\mathrm{b}^{*}\right)$, considerando a média de três leituras realizadas em diferentes pontos da superfície externa e interna das diferentes formulações das salsichas (Ramos \& Gomide, 2007).

\subsection{Perfil tecnológico}

As características tecnológicas das salsichas foram realizadas no laboratório de análise físico-química de alimentos do Campus III, Bananeiras - PB. Foi mensurada a estabilidade de emulsão (EE), segundo Parks \& Carpenter (1987), onde foram pesadas 50 gramas de amostra em embalagem de polietileno de baixa densidade e submetida a uma temperatura de $75^{\circ} \mathrm{C}$ por aproximadamente 1 hora. Após esse período, o exsudado formado dentro da embalagem foi removido e as amostras foram pesadas novamente. A perda de peso por cocção (PPC) foi realizada calculando a diferença de peso inicial das amostras antes do cozimento e depois do cozimento. A perda de peso por exsudação (PPE) foi realizada com as salsichas inteiras de aproximadamente 80 gramas cada uma calculando a diferença de peso das amostras embaladas a vácuo pela liberação de líquido exsudado antes e após um período de 24 horas em temperatura de refrigeração a $4{ }^{\circ} \mathrm{C}$. A força de cisalhamento (FC) foi determinada em um texturômetro TA - TX 2i (Stable Micro Systems), medindo-se a força da seção transversal das salsichas conforme Yotsuyanagi, (2014). Para esta análise foram utilizadas salsichas inteiras com aproximadamente 80 gramas, e as amostras foram colocadas sobre um suporte no centro da fenda onde a lâmina se movimentava. As amostras foram cisalhadas pelas lâminas, movendo-se a uma velocidade de $8,3 \mathrm{~mm} / \mathrm{s}$ na direção descendente.

\subsection{Análise microbiológica}

As análises microbiológicas foram realizadas no Laboratório de Microbiologia de Alimentos da Universidade Federal da Paraíba, Campus III, Bananeiras - PB. Os procedimentos metodológicos utilizados na condução das análises foram os descritos pela (American Public Health Association, 2001). Os microorganismos pesquisados foram Coliformes a $45^{\circ} \mathrm{C}$, Estafilococos coagulase positiva, Clostridium perfrigens e Salmonella sp, conforme estabelece a RDC ${ }^{\circ} 12$ de 2 de Janeiro de 2001, da Agência Nacional de Vigilância Sanitária (Brasil, 2001). Os resultados para Coliformes a $45^{\circ} \mathrm{C}$ foram expressos como o Número mais Provável Por Grama (NMP/g). Para Estafilococos coagulase positiva e Clostridium perfringens foram 
expressos como Unidades Formadoras de Colônia por Grama (UFC/g) e Salmonella sp foi expressa como presente ou ausente.

\subsection{Análise sensorial}

Este estudo foi submetido ao Comitê de Ética e Pesquisa da Universidade Federal da Paraíba e aprovado sob o protocolo $\mathrm{n}^{\mathrm{o}}$ 46789215.0.0000.5188. A análise sensorial foi realizada no Laboratório de Análise Sensorial de Alimentos da Universidade Federal da Paraíba (UFPB) com a participação de um painel de 100 provadores não treinados, composto por estudantes universitários e equipe técnica. A avaliação constou de três diferentes testes, como segue: teste de aceitação utilizando uma escala hedônica de 9 pontos $(9=$ Gostei extremamente e 1 desgostei extremamente), avaliando a impressão global no final; o teste de intenção de compra, realizado com escala de 5 pontos ( $1=$ certamente não compraria a 5 certamente compraria), e o teste de preferência, em que os provadores classificaram as amostras de cada tratamento quanto ao mais preferido para o menos preferido. Os três (3) testes foram realizados de acordo com os atributos avaliados de cor, aparência, textura e sabor. As avaliações foram realizadas em cabines individuais, e três amostras em torno de $10 \mathrm{~g}$ de salsichas foram apresentadas aos provadores em copos descartáveis codificados com números aleatórios de três dígitos.

\subsection{Análise estatística}

Para análise estatística, utilizou-se o delineamento inteiramente casualizado (DIC). Os dados foram submetidos à análise de variância (ANOVA) para avaliar a existência de diferenças significativas entre as médias. As diferenças foram avaliadas pelo teste de Tukey, com nível de significância de 5\%, utilizando o software Assistat (Statistical Assistance) versão 7.7 beta.

\section{Resultados e discussão}

\subsection{Composição centesimal, pH e atividade de água}

Os resultados que representam a composição centesimal das salsichas elaboradas com redução de gordura e adicionadas de inulina estão expressos na Tabela 2. O percentual lipídico nas formulações F2 e F3 em que foi reduzido o teor de gordura não apresentaram diferença significativa $(5,64 \%$ e $4,26 \%)$, porém ambas as formulações mostraram ser diferente $(p<0,05)$ da formulação controle $(\mathrm{F} 1=6,32 \%)$, observando que, com um aumento na incorporação de inulina, o percentual de gordura foi ficando menor, como mostrado na formulação $(\mathrm{F} 3=4,26 \%)$. Esse baixo percentual de gordura é atribuído à baixa quantidade de gordura que foi substituída pela inulina adicionada nesta formulação. A incorporação de inulina não afetou significativamente $(p<0,05)$ o teor de umidade, nem o teor de proteínas após o cozimento.

O teor de cinzas aumentou significativamente $(p<0,05)$ na formulação (F3) com a incorporação de $100 \%$ de inulina. Como a inulina possui um conteúdo de cinzas muito baixo, em torno de $0,2 \%$ em cinzas de matéria seca, esse aumento no percentual de cinzas da formulação F3 pode estar associado a uma maior fixação de minerais voláteis promovidos pela redução total da gordura (Franck, 2002). Os resultados obtidos neste estudo para cinzas estiveram semelhantes aos resultados encontrados por Hennelly et al., (2006), que desenvolveram carnes picadas com redução de gordura usando inulina e proteínas do plasma bovino como substitutos da gordura. Quanto ao teor de carboidratos, notaram-se diferenças significativas $(p<0,05)$ para as três formulações testadas, tendo em vista que a formulação (F3) teve o maior valor, o que era esperado, uma vez que nesta formulação foi adicionado maior percentual de inulina, que é uma fibra prebiótica. A incorporação de inulina em substituição à gordura na formulação das salsichas não alterou os níveis de $\mathrm{pH}$ e atividade de água. A ausência de diferenças significativas comprova esta hipótese. Devitte \& Dinon (2011), em estudo com adição de fibras em mortadelas, constataram que não houve diferença significativa $(p<0,05)$ entre as amostras. 
Tabela 2. Composição centesimal, pH, atividade de água e perfil tecnológico das salsichas elaboradas com redução parcial e total de gordura e adição de inulina.

\begin{tabular}{cccc}
\hline \multirow{2}{*}{ Parâmetros avaliados } & \multicolumn{3}{c}{ Formulações } \\
\cline { 2 - 4 } & F1 & F2 & F3 \\
\hline Umidade & $70,93 \pm 0,14^{\mathrm{a}}$ & $71,35 \pm 0,33^{\mathrm{a}}$ & $68,32 \pm 0,55^{\mathrm{a}}$ \\
\hline Lipídeos & $6,32 \pm 1,0^{\mathrm{a}}$ & $5,64 \pm 0,09^{\mathrm{b}}$ & $4,26 \pm 0,23^{\mathrm{b}}$ \\
\hline Proteínas & $19,28 \pm 0,68^{\mathrm{a}}$ & $19,08 \pm 0,76^{\mathrm{a}}$ & $19,43 \pm 0,32^{\mathrm{a}}$ \\
\hline Cinzas & $1,58 \pm 0,05^{\mathrm{b}}$ & $1,53 \pm 0,07^{\mathrm{b}}$ & $2,0 \pm 0,05^{\mathrm{a}}$ \\
\hline Carboidratos & $1,94 \pm 0,01^{\mathrm{c}}$ & $2,40 \pm 0,1^{\mathrm{b}}$ & $5,97 \pm 0,02^{\mathrm{a}}$ \\
\hline pH & $6,27 \pm 0,10^{\mathrm{a}}$ & $6,28 \pm 0,005^{\mathrm{a}}$ & $6,37 \pm 0,01^{\mathrm{a}}$ \\
\hline Atividade de água & $0,992 \pm 0,06^{\mathrm{a}}$ & $0,993 \pm 0,001^{\mathrm{a}}$ & $0,988 \pm 0,004^{\mathrm{a}}$ \\
\hline PPC\% & $7,15 \pm 0,45^{\mathrm{a}}$ & $4,17 \pm 0,64^{\mathrm{b}}$ & $7,48 \pm 0,005^{\mathrm{a}}$ \\
\hline EE\% & $88 \pm 0,04^{\mathrm{b}}$ & $90,12 \pm 0,03^{\mathrm{a}}$ & $82 \pm 0,14^{\mathrm{c}}$ \\
\hline PPE\% & $1,88 \pm 1,12^{\mathrm{c}}$ & $1,94 \pm 0,48^{\mathrm{b}}$ & $2,32 \pm 0,87^{\mathrm{a}}$ \\
\hline Força de cisalhamento $(\mathrm{Kgf})$ & $1,88 \pm 0,86^{\mathrm{a}}$ & $1,1 \pm 0,23^{\mathrm{b}}$ & $0,67 \pm 1,56^{\mathrm{c}}$ \\
\hline
\end{tabular}

F1: Formulação controle, sem redução de gordura; F2: Formulação com redução parcial (50\%) de gordura e adição de 50\% de inulina; F3: Formulação com redução total $(100 \%)$ de gordura e adição de $100 \%$ de inulina; n: Nove (9) amostras para cada tratamento; PPC: Perda de peso por cozimento; EE: Estabilidade da emulsão; PPE: Perda de peso por exsudação. Valores com letras minúsculas diferentes sobrescritas na mesma linha representam as diferenças significativas pelo teste de Tukey a $5 \%$ de probabilidade

Com relação aos resultados do perfil tecnológico, a formulação (F2) apresentou os melhores valores para perda de peso por cozimento e estabilidade da emulsão, sugerindo que a redução parcial da gordura por inulina é uma alternativa tecnicamente viável.

A estabilidade da emulsão (EE) expressa a quantidade de líquido (água e/ou gordura) exsudado após o cozimento do produto. Quanto maior a estabilidade da emulsão, menor é a perda de líquidos e mais estável é o produto em relação ao tratamento térmico (Barretto et al., 2015). Os resultados demonstraram que a formulação (F2), onde a gordura foi substituída parcialmente por inulina, apresentou maior estabilidade $(p<0.05)$. Com relação a um aumento na estabilidade da emulsão, resultado semelhante foi relatado por Álvarez \& Barbut (2013), acrescentando inulina em massa de carne cozida. Resultado similar ao da presente pesquisa foram encontrados por Henning et al. (2016), que observaram valores acima de $72,2 \%$, ao substituírem a gordura por fibras de abacaxi em salsicha de carne bovina.

Com relação ao parâmetro de força de cisalhamento, observam-se diferenças significativas $(p<0,05)$ para todos os tratamentos testados. Assim, estima-se uma relação positiva entre o teor de inulina e a maciez, resultando em uma menor resistência ao corte no tratamento (F3), comprovado pelo menor valor encontrado. Por conseguinte, Mendoza et al. (2001) utilizaram inulina como substituto da gordura em salsichas fermentadas e secas e observaram uma redução na dureza do produto, mas não conseguiram obter um produto que apresentasse uma textura igual a um produto com teor total de gordura, uma vez que as salsichas eram mais duras do que as amostras padrão (teor total de gordura). No entanto no presente estudo, com a adição de $100 \%$ de inulina, obteve-se uma salsicha mais macia do que o tratamento padrão (F1), diferindo dos resultados encontrados por Mendoza et al. (2001).

\subsection{Cor instrumental}

Os valores correspondentes à cor das salsichas formuladas com teor reduzido de gordura e adição de inulina estão presentes na Tabela 3. Os parâmetros mensurados foram a Luminosidade $\left(\mathrm{L}^{*}\right)$, intensidade de cor verde-vermelho (a*) e intensidade de cor azul-amarelo $\left(b^{*}\right)$. 
Tabela 3. Perfil colorimétrico de salsichas elaboradas com redução parcial e total de gordura e adicionada de inulina.

\begin{tabular}{cccc}
\hline Parâmetros avaliados & F1 & F2 & F3 \\
\hline \multicolumn{5}{c}{ Superfície interna } \\
\hline $\mathrm{L}^{*}$ & $26,56 \pm 0,64^{\mathrm{b}}$ & $30,46 \pm 0,68^{\mathrm{a}}$ & $29,53 \pm 0,21^{\mathrm{a}}$ \\
\hline $\mathrm{a}^{*}$ & $3,68 \pm 0,22^{\mathrm{a}}$ & $4,83 \pm 0,25^{\mathrm{a}}$ & $4,24 \pm 0,40^{\mathrm{a}}$ \\
\hline $\mathrm{b}^{*}$ & $33,73 \pm 0,18^{\mathrm{b}}$ & $32,69 \pm 0,88^{\mathrm{b}}$ & $43,05 \pm 0,15^{\mathrm{a}}$ \\
\hline $\mathrm{L}^{*}$ & Superfície externa & \\
\hline $\mathrm{a}^{*}$ & $27,93 \pm 0,91^{\mathrm{a}}$ & $27,44 \pm 0,53^{\mathrm{a}}$ & $26,75 \pm 0,32^{\mathrm{a}}$ \\
\hline $\mathrm{b}^{*}$ & $2,36 \pm 0,05^{\mathrm{a}}$ & $2,96 \pm 0,17^{\mathrm{a}}$ & $2,23 \pm 0,33^{\mathrm{a}}$ \\
\hline
\end{tabular}

F1: Formulação controle, sem redução de gordura; F2: Formulação com redução parcial (50\%) de gordura e adição de 50\% de inulina; FT3: Formulação com redução total (100\%) de gordura e adição de $100 \%$ de inulina. n: Nove (9) amostras para cada tratamento. Valores com letras minúscula diferente sobrescrita na mesma linha representam as diferenças significativa pelo teste de Tukey a $5 \%$ de probabilidade

Nas amostras de salsichas, aquelas em que houve redução parcial e total de gordura, o parâmetro $L^{*}$ foi afetado significativamente $(p<0,05)$ pela inclusão parcial e total de inulina quando comparadas com amostra padrão (F1). Pode-se observar que a inclusão de inulina tornou a superfície interna das salsichas (F2 e F3) mais luminosa, o que pode ser provavelmente resultado da maior intensidade de coloração branca da inulina; no entanto, e notável que os valores para $L^{*}$ foram baixos para todos os tratamentos. Alguns autores (Cáceres et al., 2004; Grigelmo-Miguel et al., 1999) associam valores menores de L * a produtos cárneos com baixo teor de gordura, corroborando os resultados encontrados na pesquisa. A intensidade de cor vermelha não apresentou diferenças significativas entre os tratamentos tanto para a superfície interna e externa das amostras de salsicha de frango. Com relação aos valores de a*, Santos (2017) observou em seu estudo que concentrações de inulina como substituto da gordura em mortadela não promoveu diferença significativa para a intensidade de cor vermelha $\left(\mathrm{a}^{*}\right)$. Esse mesmo comportamento foi observado no estudo de Faria et al. (2015), em que não observaram diferença significativa entre os tratamentos para o parâmetro a* em salsichas formuladas com teor reduzido de gordura, adicionado de pele de porco e celulose amorfa. Já com relação ao parâmetro $b^{*}$ para a superfície interna, a tonalidade de cor amarela na formulação (F3) apresentou o maior valor ( $p<0,05)$, quando comparada às demais amostras estudadas (F1 e F2). Quando se observa a superfície externa das amostras à formulação padrão (F1), foi a que mostrou o maior valor $(p<0,05)$. Neste contexto, de Souza Paglarini et al. (2019) estudaram a utilização de uma emulsão gel funcional utilizando a inulina como ingrediente principal na substituição da gordura de porco em mortadela bolonhesa. Observou-se neste estudo que, à medida que foi aumentando a concentração da emulsão gel, os valores de $b^{*}$ foram reduzidos, diferindo significativamente da formulação controle. Este estudo corrobora os resultados encontrados na presente pesquisa, onde pode notar uma redução no valor de $b^{*}$ para a formulação F3. No estudo de Yunes et al. (2013), ele relata que a comparação dos parâmetros colorimétricos é especialmente difícil, pela cor ser altamente específica, podendo alterar mediante mínima modificação em uma formulação, onde a alteração somente de alguns ingredientes pode modificar a cor do produto.

\subsection{Análise microbiológica}

Com relação o perfil microbiológico, a legislação brasileira ( $\left.R D C n^{0} 12\right)$ estabelece que salsichas aptas para o consumo humano devem apresentar um limite máximo de $10^{3}$ ou $3,0 \log \mathrm{NMP} / \mathrm{g}$ para coliformes a $45^{\circ} \mathrm{C}, 3 \times 10^{3}$ ou 3,47 log UFC/g para Estafilococos coagulase positiva, $5 \times 10^{2}$ ou 2,69 log UFC/g para Clostridium sulfito redutor e ausência para Salmonella sp. Assim, os três tratamentos de salsichas estiveram dentro dos padrões preconizados pela legislação para todos os micro-organismos pesquisados, sendo que para coliformes a $45{ }^{\circ} \mathrm{C}$ os tratamentos apresentaram valores menores que 3,0 log NMP/g. Para Estafilococos coagulase positiva, os tratamentos $\mathrm{F} 2$ e F3, os quais tiveram redução parcial e total de gordura, apresentaram os menores valores em $\log (2,74$ a 2,78 log UFC/g) para este micro-organismo. Em relação à Clostridium 
perfringens, os três tratamentos apresentaram um valor de 2,0 log UFC/g e ausência para Salmonella sp. Sendo assim, ressalta-se que todo o processo de fabricação das salsichas foi conduzido em condições higiênico-sanitárias adequadas.

\subsection{Avaliação sensorial}

As três formulações de salsichas não apresentaram diferença significativa $(p>0,05)$ para os atributos sensoriais avaliados. Em relação à cor, os três tratamentos variaram entre 6,32, 6,30 e 6,44, enquanto para a aparência, os valores ficaram entre 6,33, 6,70 e 6,59. A textura também não foi afetada, e os valores variaram entre 6,38,6,39 e 6,55. O sabor variou entre 6,43,6,48 e 6,88. Esses resultados contribuíram para uma boa aceitação durante a avaliação geral das formulações de salsichas, principalmente para os tratamentos 2 e 3 contendo a redução de gordura e inclusão da inulina, onde foram semelhantes ao tratamento controle. Isso sugeriu que a inclusão parcial e total de inulina contribuiu para manter a qualidade sensorial das salsichas, mesmo com a gordura reduzida. Todos os provadores classificaram as amostras dos diferentes tratamentos na categoria 6,0 da escala hedônica no qual representa o conceito "gostei ligeiramente". Os resultados para o teste de intenção de compra variaram entre 3,50, 3,43 e 3,56 entre os três tratamentos. Desta forma, os provadores classificaram as amostras na categoria 3,0 a 3,5, destacando-se o conceito "talvez comprasse/talvez não comprasse". Em estudos similares com salsichas e mortadela, foi constatado que a utilização de fibra dietética como substituto da gordura não alterou os atributos sensoriais (Choe et al., 2013; Devitte \& Dinon, 2011). Já Furlán et al. (2014) desenvolveram carnes picadas com redução de gordura usando inulina e proteínas plasmáticas como substitutos da gordura e não observaram diferenças significativas $(p<0,05)$ para os atributos sensoriais de cor, sabor e gosto quando comparadas ao controle.

\section{Conclusões}

A utilização da inulina para substituição parcial e total da gordura melhorou a qualidade das salsichas de frango, resultando em um produto com níveis elevados de fibra alimentar, minerais e baixo teor de gordura saturada, sem alterações nos teores de umidade, atividade de água, $\mathrm{pH}$, cor, segurança microbiológica e com boa aceitação sensorial pelos provadores. Assim, a substituição parcial e total da gordura saturada por inulina é viável na elaboração de salsichas de frango. Porém, mais estudos são essenciais para que sejam utilizadas estratégias que possam minimizar os impactos da redução total desse tipo gordura na estabilidade da emulsão (EE) e perda de peso por exsudação de salsichas de frango.

\section{Referências}

Almeida, A. L. (2015). A desconstrução de um vilão. Revista Nacional da Carne, 457, 50-55.

Álvarez, D., \& Barbut, S. (2013). Effect of inulin, $\beta$-glucan and their mixtures on emulsion stability, color and textural parameters of cooked meat batters. Meat Science, 94(3), 320-327. PMid:23567131. http://dx.doi.org/10.1016/j.meatsci.2013.02.011

American Public Health Association - APHA. (2001). Committe on Microbiological for Foods. Compendium of methods for the microbiological examination of foods (4th ed.). Washington: APHA.

Association of Official Analytical Chemists - AOAC. (2005). Official methods of analysis of the Association Analytical Chemists (18th ed.). Gaithersburg, Maryland: AOAC.

Barretto, A. C. S., Pacheco, M. T. B., \& Pollonio, M. A. R. (2015). Effect of the addition of wheat fiber and partial pork back fat on the chemical composition, texture and sensory property of low-fat bologna sausage containing inulin and oat fiber. Food Science and Technology (Campinas), 35(1), 100-107. http://dx.doi.org/10.1590/1678-457X.6496

Bernadino Filho, R., Oliveira, C. P., Gomes, Q. O., Maniçoba, B. B., \& Pereira, P. B. M. (2013). Avaliação microbiológica e sensorial de hambúrguer bovino prebiótico com baixo teor de gordura. Revista Verde, 8(2), 190-195.

Bolumar, T., Toepfl, S., \& Heinz, V. (2015). Fat reduction and replacement in dry-cured fermented sausage by using high pressure processing meat as fat replacer and olive oil. Polish Journal of Food and Nutrition Sciences, 65(3), 175-182. http://dx.doi.org/10.1515/pjfns-2015-0026

Brasil. Ministério da Saúde. Agência Nacional de Vigilância Sanitária. (2001). Resolução RDC no12 de 2 de janeiro de 2001. Regulamento técnico de padrões microbiológicos para alimentos. Diário Oficial [da] República Federativa do Brasil, Brasília. 
Brewer, M. S. (2012). Reducing the fat content in ground beef without sacrificing quality. Meat Science, 91(4), 385-395. PMid:22444664. http://dx.doi.org/10.1016/j.meatsci.2012.02.024

Cáceres, E., García, M. L., Toro, J., \& Selgas, M. D. (2004). The effect of fructooligosaccharides on the sensory characteristics of cooked sausages. Meat Science, 68(1), 87-96. PMid:22062011. http://dx.doi.org/10.1016/j.meatsci.2004.02.008

Choe, J. H., Kim, H. Y., Lee, J. M., Kim, Y. J., \& Kim, C. J. (2013). Quality of frankfurter-type sausages with added pig skin and wheat fiber mixture as fat replacers. Meat Science, 93(4), 849-854. PMid:23313971. http://dx.doi.org/10.1016/j.meatsci.2012.11.054

Devitte, S. L., \& Dinon, S. (2011). Mortadela adicionada de fibras e com substituição parcial da gordura por carragena e pectina (Trabalho de Conclusão de Curso). Universidade Tecnológica Federal do Paraná, Medianeira.

Faria, M. O., Cipriano, T. M., Cruz, A. G., Santos, B. A., Pollonio, M. A. R., \& Campagnol, P. C. B. (2015). Properties of bologna-type sausages with pork back- fat replaced with pork skin and amorphous cellulose. Meat Science, 104, $44-51$. PMid:25688689. http://dx.doi.org/10.1016/j.meatsci.2015.02.002

Franck, A. (2002). Technological functionality of inulin and oligofructose. British Journal of Nutrition, 87(2, Supl. 2), S287-S291. PMid:12088531. http://dx.doi.org/10.1079/BJNBJN/2002550

Furlán, L. T. R., Padilla, A. P., \& Campderrós, M. E. (2014). Development of reduced fat minced meats using inulin and bovine plasma proteins as fat replacers. Meat Science, 96(2), 762-768. PMid:24200568.

http://dx.doi.org/10.1016/j.meatsci.2013.09.015

Grigelmo-Miguel, N., Abadías-Serós, M. I., \& Martín-Belloso, O. (1999). Characterisation of low-fat high-dietary fibre frankfurters. Meat Science, 52(3), 247-256. PMid:22062572. http://dx.doi.org/10.1016/S0309-1740(98)00173-9

Hennelly, P. J., Dunne, P. G., O'sullivan, M., \& O'riordan, E. D. (2006). Textural, rheological and microstructural properties of imitation cheese containing inulin. Journal of Food Engineering, 75(3), 388-395.

http://dx.doi.org/10.1016/j.jfoodeng.2005.04.023

Henning, S. S., Tshalibe, P., \& Hoffman, L. C. (2016). Physico-chemical properties of reduced-fat beef species sausage with pork back fat replaced by pineapple dietary fibres and water. Food Science and Technology (Campinas), 74, 92-98.

Horita, C. N., Morgano, M. A., Celeghini, R. M. S., \& Pollonio, M. A. R. (2011). Physico-chemical and sensory properties of reduced fat mortadella prepared with blends of calcium, magnesium and potassium chloride as partial substitutes for sodium chloride. Meat Science, 89(4), 426-433. PMid:21645975. http://dx.doi.org/10.1016/j.meatsci.2011.05.010

Hue, C. K. (2011). O mercado de frios no Brasil: uma estimação de demanda a partir de um Modelo AIDS em três Estágios. (Dissertação de Mestrado. Economia). Departamento de Economia da Fundação Getúlio Vargas, São Paulo.

Hygreeva, D., Pandey, M. C., \& Radhakrishna, K. (2014). Potential applications of plant based derivatives as fat replacers, antioxidants and antimicrobials in fresh and processed meat products. Meat Science, 98(1), 47-57. PMid:24845336. http://dx.doi.org/10.1016/j.meatsci.2014.04.006

Marchetti, L., Muzzio, B., Cerrutti, P., Andres, S. C., \& Califano, A. N. (2017). Bacterial nanocellulose as novel additive in lowlipid low-sodium meat sausages. Effect on quality and stability. Food Structure, 14, 52-59. http://dx.doi.org/10.1016/j.foostr.2017.06.004

Mendoza, E., García, M. L., Casas, C., \& Selgas, M. D. (2001). Inulin as fat substitute in low fat, dry fermented sausages. Meat Science, 57(4), 387-393. PMid:22061711. http://dx.doi.org/10.1016/S0309-1740(00)00116-9

Park, K. S., Choi, Y. S., Kim, H. Y., Kim, H. W., Song, D. H., Hwang, K. E., Choi, S. G., \& Kim, C. J. (2012). Quality characteristics of chicken emulsion sausages with diferente levels of makgeolli lees fiber. Han-gug Chugsan Sigpum Hag-hoeji, 32(1), 54-61. http://dx.doi.org/10.5851/kosfa.2012.32.1.54

de Souza Paglarini, C., de Figueiredo Furtado, G., Honório, A. R., Mokarzel, L., da Silva Vidal, V. A., Ribeiro, A. P. B., Cunha, R. L., \& Pollonio, M. A. R. (2019). Functional emulsion gels as pork back fat replacers in Bologna sausage. Food structure, 20, 100105. http://dx.doi.org/10.1016/j.foostr.2019.100105

Parks, L. L., \& Carpenter, J. A. (1987). Functionality of six non meat proteins in meat emulsion systems. Journal of Food Science, 2(2), 271-274. http://dx.doi.org/10.1111/j.1365-2621.1987.tb06590.x

Ramos, E. M., \& Gomide, L. A. M. (2007). Avaliação da qualidade da carne: fundamentos e metodologias.

Saad, S. M. I., Cruz, A. G., \& Faria, J. A. F. (2011). Probióticos e prebióticos em alimentos: fundamentos e aplicações tecnológicas (pp. 23-45). São Paulo: Editora Varela.

Sah, B. N. P., Vasiljevic, T., Mckechnie, S., \& Donkor, O. N. (2016). Physicochemical,textural and rheological properties of probiotic yogurt fortified with fibre-rich pineapple peel powder during refrigerated storage. Lebensmittel-Wissenschaft undTechnologie. Food Science and Technology (Campinas), 65, 978-986.

Santos, S. G. P. (2017). Utilização de gel a base de pele suína e inulina como substituto de gordura em mortadela (Dissertação de mestrado). Instituto Federal de Educação, Ciência e Tecnologia do Triângulo Mineiro, Uberaba.

Slima, S. B., Ktari, N., Triki, M., Trabelsi, I., Abdeslam, A., Moussa, H., Makni, I., Herrero, A. M., Jimenez-Colmenero, F., RuizCapillas, C., \& Salah, R. B. (2018). Effects of probiotic strains, Lactobacillus plantarum TN8 and Pediococcus acidilactici, on microbiological and physico-chemical characteristics of beef sausages. Food Science and Technology (Campinas), 92, 195203.

United States Department of Agriculture - USDA. Economic Research Service. (2002). Changing consumer demands create opportunities for U.S. food system. Food Review, 19-22. 
Yotsuyanagi, S. (2014). Impactos tecnológicos, sensoriais e microbiológicos da redução do teor de sódio em salsicha (Tese de doutorado). Escola Superior de Agricultura "Luiz de Queiroz, Piracicaba. http://dx.doi.org/10.11606/D.11.2014.tde-15092014145223.

Yunes, J. F. F., Terra, N. N., Blanquez, F. J. H., Milani, L. I. G., \& Scheeren, M. B. (2013). Efeito da substituição da gordura suína nas características de qualidade, estabilidade oxidativa e microestrutura de mortadela. Semina Ciências Agrárias, 34(3), 1-13. http://dx.doi.org/10.5433/1679-0359.2013v34n3p1205.

Funding: Conselho Nacional de Desenvolvimento Científico e Tecnológico, Brasil, 2015-2016. 